\title{
Energy Scavenging Technology and Components in WSN
}

\author{
Sutapa Sarkar, Hameem Shanavas .I, Bhavani V \\ MVJ College of Engineering, Bangalore, India \\ Email: sutapasarkar11@rediffmail.com;hameemshan@gmail.com;bhavanichoudary22@gmail.com
}

\begin{abstract}
With the evolution of modern technology wireless sensor nodes are finding a lot of applications in day to day life starting from smart home system to military surveillance. The primary building block of a wireless sensor network is a spatially distributed set of autonomous sensor nodes or motes. In order to design a wireless sensor network it is necessary to understand the structure and working of a sensor node. The sensor nodes can be considered as tiny battery powered computers that consists of a computing subsystem, communication subsystem, sensor subsystem, power subsystem. In this paper we review the features of these subsystems so that it is easy for the application developer to quickly understand and select the type of component for building customized sensor node platform. In this paper we have studied the features of different microprocessors and transceivers properties used in sensor nodes. We also study the classifications of sensors based on applications, the relevant sensor parameters, and different storage devices with their properties. This paper can be a ready reference to beginners interested in this field. One more major problem of wireless sensor network application that should be addressed is the limited lifetime of sensor nodes due to energy constraints. We also review how energy harvesting can increase the lifetime of a wireless sensor network and the possible methods that can be implemented for energy harvesting.
\end{abstract}

Index Terms - Wireless sensor nodes, Energy harvesting Methods, Energy efficient routing protocols.

\section{INTRODUCTION}

A wireless sensor network (WSN) is a wireless network that consists of a spatially distributed set of autonomous wireless sensor nodes. Nodes are commonly referred to as motes. The number of nodes in a sensor network can be up to hundreds of thousands. The nodes are tiny computing devices, each equipped with sensors (type of sensor depends on application), a wireless radio, a processor, and a power source. The sensor nodes can be considered as tiny battery powered computers. Nodes take the data from the attached sensor nodes and using the on-board processor perform simple

Manuscript received October 1, 2013; revised December 14, 2013; accepted December 18, 2013. computations and transmit only the required and partially processed data [1]. Wireless sensor network has attracted a lot of research attention due to its potential applications.

But there are a number of challenges that are to be overcome. Depending on the type of sensor it can have military applications, Environmental applications, health applications, Home applications and commercial applications[1].The first sensor node was developed during the $70 \mathrm{~s}$.With the advent of micro-electromechanical system, and wireless communication technology low power consuming wireless sensor nodes have been developed.

One important research challenge in the field of wireless sensor networks is the battery lifetime. Sensor networks consist of a large number of unattended nodes working in harsh environment. The sensor nodes are conventionally powered by batteries. But batteries have a limited lifetime. So once the power supply from the portable energy source (conventionally batteries) used in the sensor node is over the node becomes useless. In some applications it may not be feasible to replace the battery if the node is embedded in a building or located at some place that is difficult to reach. This dependency on battery is inefficient and also it posses risk to the environment as the battery may leak its contents in the environment leading to pollution and possible corrosion of the surrounding medium.

This constraint can be overcome by using energy harvesting from suitable sources according to the application concerned. This paper describes the structural components of wireless sensor nodes, the possible methods of energy harvesting to improve the lifetime ff the sensor networks and the possible applications.

Zigbee (IEEE 802.15.4) is the standard commonly used in wireless sensor node communication. Bluetooth can be an alternative for interoperability with computer, cellular phone etc. But with Bluetooth power consumption is higher.

The rest of the paper is organized as follows: Section II presents a description of the different components of the wireless sensor node. It also provides a comparative study of the features of different microcontrollers and transceivers used, description of the types of sensors based on the application and also the parameters relevant to a type of sensor. This section also consists of a study of the battery parameters used in different sensor nodes. Section III presents a description of the energy 
harvesting methods, Section IV gives a brief description of energy harvesting routing protocols, section $\mathrm{V}$ describes the wireless sensor network applications and section VI is the conclusion of the paper.

\section{WIRELESS SENSOR NODE COMPONENTS}

The number of sensor nodes in a network is a variable quantity and also the size of the nodes may vary. But basically all the sensor nodes are made of the following modules: sensor modules, wireless communication module, a CPU, and a power source[2]. The sensor network uses different routing protocols with the aim of minimizing the energy conservation while maintaining the accuracy of data delivery from the source to destination node.

\section{A. Processor module}

The computing subsystem performs the required computation and controlling operation on the wireless sensor node components. It consists of the following parts: A microcontroller and a storage unit (optional in some of the commercially available WSN). Depending on the power availability and application a range of microcontrollers are used in different commercially available motes. Motes support Active, Idle or sleep mode of operation. The Processor energy consumption, denoted as $E_{c p u}$ is the sum of the state energy consumption $\mathrm{E}_{\mathrm{cpu} \text {-state }}$ and the state-transition energy consumption $\mathrm{E}_{\mathrm{cpu} \text {-change. }}$

$$
\begin{aligned}
& E_{c p u}=E_{\text {cpu-state }}+E_{\text {cpu-change }}= \\
& \sum_{i=1}^{m} P_{\text {cpu-state }}(i) T_{\text {cpu-state }}(i)+ \\
& \sum_{j=1}^{n} N_{\text {cpu-change }}(j) e_{\text {cpu-change }}(j)
\end{aligned}
$$

Where $E_{\text {cpu-state }}=$ sum of state energy consumption, $\mathrm{E}_{\text {cpu-change }}=$ the state-transition energy consumption, $\mathrm{i}=$ $1,2, \ldots \mathrm{m}$ where $\mathrm{m}$ is the number of processor state, $\mathrm{j}=$ $1,2, \ldots \mathrm{n}$ with $\mathrm{n}$ as the number of state transition [2].

The range of microcontrollers can vary from low power 8 bit ones to powerful processors such as [3]: Atmel AT90LS8535, Atmel Atmega 128L, Atmel AT91FR4081A, PIC 18F452, 8-bit AVR-like RISC 4, Chipcon CC1010 (8051), PIC 16F877, TI MSP430F149, TI MSP430F149, nRF24E1 (8051), PIC18F6720, TI MSP430F1611, Intel PXA 271, rfPIC 16F675, Cypress CY8C2764 etc. Microprocessors used can follow RISC or CISC architecture. Table-I gives a description of the microprocessors used in wireless sensor nodes. Node contains a flash memory for storing the code and RAM for storing the sensed data. A node might also contain a separate storage unit.eg micro SD card interface in SHIMMER for storing off line data up to 2 Giga Byte. The main reason for avoiding computational complexity in wireless sensor nodes is the lack of available power. For similar reason writing to micro SD card is avoided as it consumes a lot of power.

\section{B. Communication module}

The radio or communication subsystem is required for communication between the nodes and also to transmit the sensed and processed data from the corresponding node. Sensor nodes mainly use broadcasting techniques for communication. Radio frequency communication is most popular for wireless sensor nodes. This type of communication does not require line of sight operation and also with the advent of technology available in different data rates and ranges based on applications. Unlicensed ISM bands are suitable for this type of communication.chk for licensed band from country to country. Also there are many devices that use the same ISM. The presence of such devices in the proximity of WSN can cause additional interference causing poor quality communication. Zigbee (IEEE 802.15.4) is the standard commonly used in wireless sensor node communication. Bluetooth can be an alternative for interoperability with computer, cellular phone etc. But with Bluetooth power consumption is higher.

\section{Sensor module}

A sensor is a converter that measures a physical quantity and converts it into a signal that can be measured by an instrument. A sensor should be sensitive to the measured property only and should not influence it. Energy consumption in sensor module is due to analogue to digital signal conversion and signal modulation.

$$
E_{\text {sensor }}=E_{\text {on-off }}+E_{\text {off-on }}+E_{\text {sensor-run }}
$$

Where $\mathrm{E}_{\text {on-off }}=$ one time energy consumption of closing wireless sensor network. $\mathrm{E}_{\text {off-on }}=$ one time energy consumption of opening wireless sensor network and $\mathrm{E}_{\text {sensor-run }}=$ Energy consumption of sensing operations.

From different companies different sensor platforms are available e.g. WeC, Rene 1, AWAIRS 1, $\mu$ AMPS, Rene 2,DOT, Mica, BT Node, SpotOn, iMote, Telos, MicaZ that use different software like TinyOs, MicroC/OS, Smart-its, Palos etc. Table-II indicates the bandwidth and frequency of different transceivers that are commonly used in wireless sensor nodes. Table-III lists the commonly used sensor types and Table-IV lists the sensor parameters relevant to different types of sensors.

\section{Power module}

The energy required to power a node should be dependable. Usually batteries are used to power wireless sensor nodes. The external battery pack usually contains AA batteries. The battery consists of a single electrochemical cell. The power supplied by the battery depends on the chemistry of the battery depending on application it might be difficult to replace the battery. Also it is difficult to replace the batteries if a very high number of nodes are required in that application. Table$\mathrm{V}$ lists commonly used batteries and relevant parameters.

Lithium batteries are more efficient and have lower self discharge rate than $\mathrm{Ni}-\mathrm{Cd}, \mathrm{Ni}-\mathrm{MH}$ or SLA batteries. 
TABLE I. SPECIFICATIONS OF MICROPROCESSORS USED IN SENSOR NODES [4], [5], [6], [7], [8], [9], [10], [11], [12]

\begin{tabular}{|c|c|c|c|c|}
\hline CPU & $\begin{array}{c}\text { CPU } \\
\text { structure(complexity) }\end{array}$ & FLASH & RAM & $\begin{array}{c}\text { Operating } \\
\text { voltage }\end{array}$ \\
\hline Atmel AT90LS8535 & RISC & $8 \mathrm{kBytes}$ & 512 Bytes & $2.7-6.0 \mathrm{~V}$ \\
\hline ATmega128L & RISC & $128 \mathrm{k}$ & $4 \mathrm{kBytes}$ & $2.7-5.5 \mathrm{~V}$ \\
\hline Atmel & RISC & $8 \mathrm{Mbits}$ & $136 \mathrm{kBytes}$ & $2.7-3.6 \mathrm{~V}$ \\
\hline AT91FR4081A & RISC & $256-2 \mathrm{kBytes}$ & 1024 bytes & $4.0-5.5 \mathrm{~V}$ \\
\hline Atmel Atmega 163 & CISC & - & - & - \\
\hline Dragonball EZ & RISC & $32 \mathrm{kBytes}$ & 1536 Bytes & $2.0-5.5 \mathrm{~V}$ \\
\hline PIC 18F252 & RISC & $8 \mathrm{Mbits}$ & $135 \mathrm{kBytes}$ & $2.7-3.6 \mathrm{~V}$ \\
\hline Atmel & RISC & $32 \mathrm{kBytes}$ & 1536 Bytes & $2.0-5.5 \mathrm{~V}$ \\
\hline PT91FR4081 & RISC & $8 \mathrm{k}$ x 14 words & $368 x 8$ Bytes & $2.0-5.5 \mathrm{~V}$ \\
\hline PIC 16F877 & RISC & $60 \mathrm{kBytes}$ & $2 \mathrm{kBytes}$ & $1.8-3.6 \mathrm{~V}$ \\
\hline TI MSP430F149 & - & $128 \mathrm{kBytes}$ & $3840 \mathrm{Bytes}$ & $2.0-5.5 \mathrm{~V}$ \\
\hline PIC 18F6720 & RISC & $40 \mathrm{kBytes}$ & $10 \mathrm{kBytes}$ & $1.8-3.6 \mathrm{~V}$ \\
\hline TI MSP430F1611 & - & $256 \mathrm{kbytes}$ & $64 \mathrm{kBytes}$ & $2.25-3.75 \mathrm{~V}$ \\
\hline Intel PXA 271 & $8 \mathrm{kB}$ & 256 Bytes & $1.8-3.6 \mathrm{~V}$ \\
\hline TI MSP430F1232 & & & & \\
\hline
\end{tabular}

TABLE II. TRANSCEIVERS USED IN DIFFERENT SENSOR PLATFORMS

\begin{tabular}{|c|c|c|}
\hline Radio Transceiver & BW(kbps) & Frequency(MHz) \\
\hline RFM TR1000 & 10 & 916.5 \\
\hline $\begin{array}{c}\text { Conexant } \\
\text { RDSSS9M }\end{array}$ & 100 & 900 \\
\hline National LMX3162 & 1000 & 2400 \\
\hline $\begin{array}{c}\text { ZV4002 BT/ } \\
\text { CC1000 }\end{array}$ & 1000 & 2400 \\
\hline Radiometrix & 64 & 433 \\
\hline Chipcon CC1000 & 38.4 & 900 \\
\hline $\begin{array}{c}\text { Ericsson } \\
\text { ROK101007 BT }\end{array}$ & 1000 & 2400 \\
\hline Zeevo BT & 720 & 2400 \\
\hline Chipcon CC2420 & 250 & 2400 \\
\hline Nordic nRF903 & 76.8 & 868 \\
\hline Infineon TDA 5200 & 120 & 868 \\
\hline rfPIC 16F675 & 19.2 & 868 \\
\hline Chipcon CC2420 & 250 & 2400 \\
\hline Ember 250 & 250 & 2400 \\
\hline Nordic nRF24AP1 & 1000 & 2400 \\
\hline Nordic nRF24E1 & 1000 & 2400 \\
\hline $\begin{array}{c}\text { WML-C46A } \\
\text { BT/CC2420 }\end{array}$ & 250 & 2400 \\
\hline Atmel ATRF230 & 250 & 2400 \\
\hline
\end{tabular}

For this reason Lithium batteries are better choices for energy harvesting wireless sensor nodes. Lithium based batteries need a high charging current pulse for charging whereas $\mathrm{NiMH}$ can be trickle charged that is directly connected to an energy source for charging. Efforts are there to recharge the battery by generating energy from the surrounding environment, by using thermal, vibration or RF energy sources.

To increase the lifetime of wireless sensor nodes two approaches are there: One approach is the idea of energy harvesting wireless sensor nodes that has gained considerable attention recently. Another approach is to design energy efficient routing protocols increasing the lifetime of the nodes. Energy harvesting can remove dependency of wireless sensor nodes on power source.

\section{METHODS OF ENERGY HARVESTING IN WIRELESS SENSOR NODES}

Energy harvesting can be described as the process of capture, accumulation and storage of unexploited energy from circumambient environmental sources [13].The energy can be derived from solar, temperature, motion or electromagnetic. With the present technology energy harvesting is not sufficient to power large mechanical devices. But energy harvesting is an alternate energy source for small and portable devices. The general properties of a portable energy supplier are electrical properties (power density, maximum voltage and current), physical properties(size, shape, weight), environmental properties(water resistance, operating temperature range). The EH (energy harvesting) circuit should remain always active to catch this small amount of energy. The power consumption of the harvester circuit needs to be very 
TABLE III. LIST OF A FEW TYPES OF SENSORS BASED ON APPLICATIONS

\begin{tabular}{|c|c|}
\hline Types of sensors & Description \\
\hline Accelarometer & $\begin{array}{l}\text { Measures the rate of change of } \\
\text { velocity (aka Acceleration)in } \\
\text { meters per second squared } \\
(\mathrm{m} / \mathrm{s} 2) \text { or g's }\end{array}$ \\
\hline $\begin{array}{l}\text { ALS(Ambient Light } \\
\text { sensor) }\end{array}$ & $\begin{array}{l}\text { Measures visible light intensity } \\
\text { in Lux. }\end{array}$ \\
\hline $\begin{array}{c}\text { Barometer/Pressure } \\
\text { sensor }\end{array}$ & $\begin{array}{l}\text { Measures atmospheric pressure } \\
\text { in hecto-pascal }(1 \mathrm{hPa}=100 \mathrm{~Pa} \\
=1 \mathrm{millibar})\end{array}$ \\
\hline Gyrometer /Gyroscope & $\begin{array}{l}\text { Measures rotation velocity (aka } \\
\text { angular rate), in degrees per } \\
\text { second (dps) or radians per } \\
\text { second ( } \mathrm{rad} / \mathrm{s}) .\end{array}$ \\
\hline $\begin{array}{l}\text { Hygrometer /Humidity } \\
\text { Sensors }\end{array}$ & $\begin{array}{c}\text { Measures environmental \% } \\
\text { relative humidity. }\end{array}$ \\
\hline Magnetometer & $\begin{array}{c}\text { Measures magnetic field } \\
\text { strength, in Tesla }(1 \mu \mathrm{T}=10 \\
\mathrm{mG}) .\end{array}$ \\
\hline Proximity sensor & Measures object locality in $\mathrm{cm}$. \\
\hline Temperature Sensor & $\begin{array}{c}\text { Measures environmental } \\
\text { ambient temperature in Celsius } \\
(\mathrm{C}) \text {, Fahrenheit }\left({ }^{\circ} \mathrm{F}\right) \text { or Kelvin } \\
(\mathrm{K})\end{array}$ \\
\hline
\end{tabular}

sources. Also the EH circuit should be able to store the harvested energy with the minimum leakage [14]. Energy harvesting or power scavenging is best suited for applications that need continuous supply of low power, or the applications that need high power for a small duration of time.

\section{A. Solar or Photovoltaic cell}

One of the most popular energy harvesting technique is the use of solar or photovoltaic cell. In this type of energy harvesters optical energy mainly from sunlight is converted into electrical energy. Hence it is best suited for applications that have ample exposure to sun. The periods of cloud cover, snow fall affect the energy production by solar cells. The output of solar cell depends on the sunlight as well as on the load attached to it.

Silicon based cells are popular choices of solar cells. Solar cells have conversion efficiency up to $30 \%$. Solar radiation yields around $15 \mathrm{~mW} / \mathrm{cm}^{2}$ in full sunlight or $0.006 \mathrm{~mW} / \mathrm{cm}^{2}$ under bright indoor illumination [14]. Solar powered nodes are suitable for environmental monitoring applications. This type of communication requires lesser data rate and are less sensitive to delay as compared to normal operations.

TABLE IV. CHART ON SENSOR PARAMETERS (TERMINOLOGIES ADAPTED FROM COMMON INDUSTRY PRACTICES [15])

\begin{tabular}{|c|c|}
\hline Sensor type & Applicable sensor parameters \\
\hline Accelerometer & $\begin{array}{l}\text { Full Scale Range, Sensitivity Temperature Coefficient, Digital Bit Depth, Noise, } \\
\text { Cross-Axis Sensitivity, Current Consumption, Integral Non-Linearity, Output Data } \\
\text { Rate (ODR),Transition Time, Sensitivity, Filter -3dB Cutoff, Data Ready Delay, } \\
\text { Internal Oscillator Tolerance, Zero-g Offset, Zero-g Offset Temperature Coefficient }\end{array}$ \\
\hline Magnetometer & $\begin{array}{l}\text { Full Scale Range, Sensitivity Temperature Coefficient, Digital Bit Depth, Noise, } \\
\text { Cross-Axis Sensitivity, Current Consumption, Integral Non-Linearity, Output Data } \\
\text { Rate (ODR),Transition Time, Sensitivity, Filter -3dB Cutoff, Data Ready Delay, } \\
\text { Offset at Zero Magnetic Field, Acquisition Time, Offset Temperature Coefficient }\end{array}$ \\
\hline Gyrometer/Gyroscope & $\begin{array}{l}\text { Full Scale Range, Sensitivity Temperature Coefficient, Digital Bit Depth, Noise, } \\
\text { Cross-Axis Sensitivity, Current Consumption, Integral Non-Linearity, Output Data } \\
\text { Rate (ODR),Transition Time, Sensitivity, Filter -3dB Cutoff, Data Ready Delay, } \\
\text { Internal Oscillator Tolerance, State to State Transition Time, Zero Rate Bias, Zero } \\
\text { Rate Bias Temperature Coefficient, Internal Oscillator Tolerance, Root Allan } \\
\text { Variance Parameters, Linear Acceleration Sensitivity, Mechanical Resonance }\end{array}$ \\
\hline $\begin{array}{c}\text { Barometer/Pressure } \\
\text { sensor }\end{array}$ & $\begin{array}{c}\text { Full Scale Range, Digital Bit Depth ,Noise, Current Consumption, Integral Non- } \\
\text { Linearity, Transition Time, Sensitivity, Short Term Stability, Long Term Stability, } \\
\text { Over Pressure Maximum, Pressure Temperature Coefficient, Pressure Accuracy, } \\
\text { Acquisition Time, }\end{array}$ \\
\hline $\begin{array}{l}\text { Hygrometer/Humidity } \\
\text { Sensor }\end{array}$ & $\begin{array}{c}\text { Full Scale Range, Digital Bit Depth ,Noise, Current Consumption, Integral Non- } \\
\text { Linearity, Transition Time, Sensitivity, Relative Humidity Accuracy, Long Term } \\
\text { Drift, Response Time }\end{array}$ \\
\hline Temperature & $\begin{array}{l}\text { Full Scale Range, Digital Bit Depth ,Noise, Current Consumption, Integral Non- } \\
\text { Linearity, Transition Time, Sensitivity, Long Term Drift, Absolute Temperature } \\
\text { Error }\end{array}$ \\
\hline Ambient Light Sensor & $\begin{array}{l}\text { Digital Bit Depth ,Current Consumption, Transition Time, Sensitivity, ALS } \\
\text { Conversion Time vs. Maximum Detection range, ALS Measurement Accuracy, } \\
\text { Normalized Spectral Response, ALS Noise, Responsivity vs. Angle }\end{array}$ \\
\hline Proximity Sensor & Digital Bit Depth, Transition Time, Sensitivity, sensing Current Consumption \\
\hline
\end{tabular}


TABLE V. FEW RECHARGEABLE BATTERY TECHNOLOGIES [17]

\begin{tabular}{|c|r|r|c|c|c|c|}
\hline Battery Type & $\begin{array}{c}\text { Nominal } \\
\text { Voltage } \\
(\mathbf{V})\end{array}$ & $\begin{array}{c}\text { Power } \\
\text { density } \\
\text { (W/Kg) }\end{array}$ & $\begin{array}{c}\text { Efficiency } \\
(\%)\end{array}$ & $\begin{array}{c}\text { self Discharge } \\
(\% / M o n t h)\end{array}$ & $\begin{array}{c}\text { charging } \\
\text { Method }\end{array}$ & $\begin{array}{c}\text { Recharge } \\
\text { cycles }\end{array}$ \\
\hline $\begin{array}{c}\text { SLA(Sealed Lead } \\
\text { Acid) }\end{array}$ & 6 & 180 & $70-92$ & 20 & Trickle & $500-800$ \\
\hline $\begin{array}{c}\text { Ni-Cd(Nickel } \\
\text { Cadmium) }\end{array}$ & 1.2 & 150 & $70-90$ & 10 & Trickle & 1500 \\
\hline $\begin{array}{c}\text { Ni-MH(Nickel } \\
\text { Metal Hydride) }\end{array}$ & 1.2 & $250-1000$ & 66 & 20 & Trickle & 1000 \\
\hline $\begin{array}{c}\text { Li-ion } \\
\text { (Lithium ion) }\end{array}$ & 3.7 & 1800 & 99.9 & $<10$ & Pulse & 1200 \\
\hline Li-Polymer & 3.7 & 3000 & 99.8 & $<10$ & Pulse & $500-1000$ \\
\hline
\end{tabular}

\section{B. Thermoelectric generator}

The generation of electricity using a temperature gradient is referred to as thermoelectricity. A temperature difference between two junctions of a conducting material creates a potential difference. This potential difference is used by thermoelectric generators.

\section{Mechanical Vibration}

Piezoelectric: This method converts mechanical (pressure, vibration) energy into electricity. Popularly used piezoelectric materials are quartz, polycrystalline ceramic. The properties of these materials vary with age, stress and working temperature. The energy generated using piezoelectric materials can be stored in a capacitor or battery. But due to charge leakage of capacitors, rechargeable batteries are better choice. Energy harvesting piezoelectric research falls into two categories: developing optimal energy harvesting structure and designing efficient electric circuits to store the harvested energy. More than $79 \mathrm{~mW}$ power harvesting piezoelectric system has been proposed using which it is possible to power a wireless sensor node [16].

Electrostatic: The planes of initially charged varactors are separated by vibration and the corresponding mechanical energy is used to generate electrical energy. One dedicated voltage source is required for this type of energy generation to charge the capacitors initially. The harvested energy is provided by the work done against the electrostatic force between the capacitor plates.

Electromagnetic: Electromagnetic induction is a useful method of energy harvesting which is free of the effects of mechanical damping. Permanent magnets, coils and resonating cantilever beam are used for this type of energy harvesting. In electromagnetic induction voltage is generated in a conductor by changing the voltage surrounding the inductor. But because of its large size these are difficult to integrate with wireless sensor nodes. Separate voltage source is not needed for this type of energy harvesting. Maximum $0.1 \mathrm{~V}$ is produced by this type of energy harvesters [16].

\section{Far Field RF Energy Harvesting}

RF wireless transmission of data is widely established in modern days, e.g. cellular networks, radio and television networks. Because of this wide availability of wireless network considerable amount of RF energy can be detected in the environment. With proper circuitry this ambient energy can be used to power autonomous sensor nodes. With the use of this technology wireless communication infrastructure becomes a source of power without any added cost to the wireless communication service provider. RF energy harvesting uses the power that would have otherwise been wasted and absorbed in the environment.

Far field RF energy harvesting can be done in two ways: Active energy harvesting by using a dedicated energy transmitter or Passive energy harvesting using the ambient sources of energy present in environment such as propagating radio waves [18]. One possible method of RF energy harvesting is by using television broadcast energy. Energy from RF commercial broadcasting stations like TV or radio is used to supply energy to WSN. Energy is harvested using rectenna (rectifier +antenna) principle with the antenna connected to a tuner stage. The tuner selects one out of the possible commercial broadcasting channels. The selected channel is the more powerful one and to this the sensor node is connected[19].

RF energy harvesting using Rectenna: RF energy harvesting uses far field RF energy-transmission. The RF energy harvesting WSN consists of antenna that is matched with the desired frequency of operation. The antenna is connected to a rectifier. This antenna and rectifier arrangement together is called the rectenna system. The output of antenna is the usable DC power. This DC power is stored in an energy storage device before being delivered to a load. The schematic of a general RF power transmission system is shown in fig. 1 [20]. 

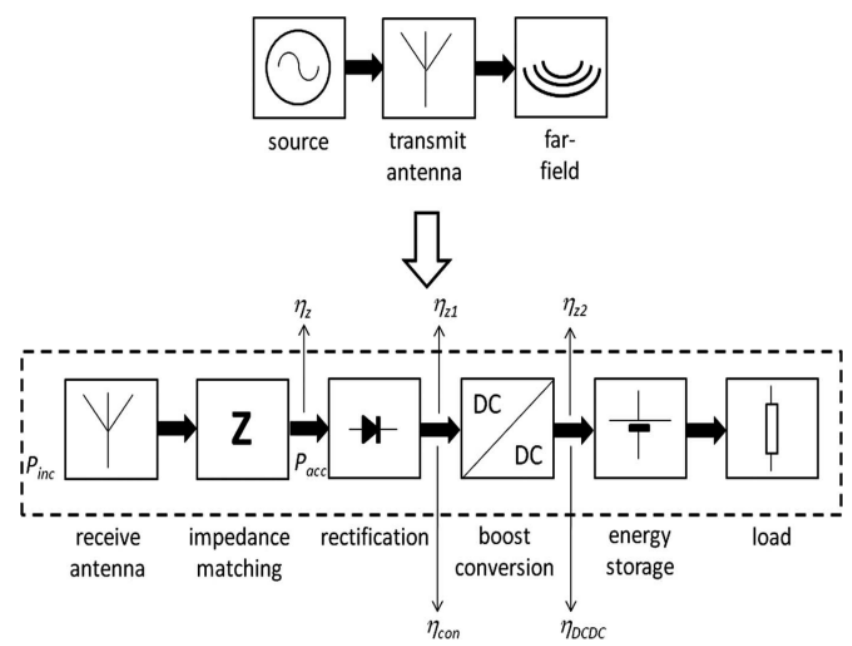

Figure. 1. Wireless RF power system, with the rectenna in the dashed box. $\mathrm{P}_{\text {inc }}$ is the incident power upon the receive antenna; $\mathrm{P}_{\mathrm{acc}}$ is the accepted power after impedance matching; _ $\mathrm{z}, \mathrm{z}_{1}$, and $z_{2}$ are the impedance matching efficiencies; _con is the rectifier power conversion efficiency; and_dcdc is the boost converter power efficiency

\section{ENERGY EFFICIENT ROUTING PROTOCOLS}

One aim of wireless sensor network research is increased lifetime of sensor nodes. This can be achieved by using energy efficient routing protocols. Some of the parameters that are useful while describing an energy efficient routing protocol are as follows: Energy per packet(Amount of energy spent when sending a packet from source to destination), Energy and reliability, Network Lifetime(when first node finishes its lifetime or a certain fraction of nodes are dead), Average Energy Dissipated(Average dissipation of energy over time), Low energy consumption, Total number of nodes alive, Total number of data signals received at Base Station, Average packet Delay, Packet delivery ratio(ratio of the number of packets received at the sinks to original number of nodes sent at the sensors), Time until the first node dies, Energy spent per round, Idle listening, Packet Size, Distance between transmitter and receiver. The energy efficient routing protocols can be divided into the following categories[2]: Based on network structure, based on communication model, based on topology, based on reliable routing. The division based on network structure can be subdivided into Flat protocols and hierarchical protocols. The communication model can be subdivided into query based protocol, coherent based protocols and negotiation based protocol. Topology based division can be subdivided into location based protocols and mobile agent based protocols. Reliable routing has two types: Multipath based protocols and QoS based protocols.

\section{APPLICATIONS}

Wireless sensor networks find a wide range of application in military, environmental, health, smart homes, space exploration and other commercial domains.
They can be used for certain event detection or continuous monitoring of the target. Rapid deployment and fault tolerance feature makes it an attractive technique for military applications. In the domain of environment tracking sensor networks are used for monitoring bird or animal movements, monitoring environmental conditions that affect corps, flood detection, pollution study, chemical and biological detection etc. A few health applications of wireless sensor networks are diagnostics and drug administration in the hospitals, telemonitoring of human physiological data. Sensor nodes used in home appliances can interact with each other remotely. Air conditioners use sensors to centrally control the environment of an office building.

\section{CONCLUSIONS}

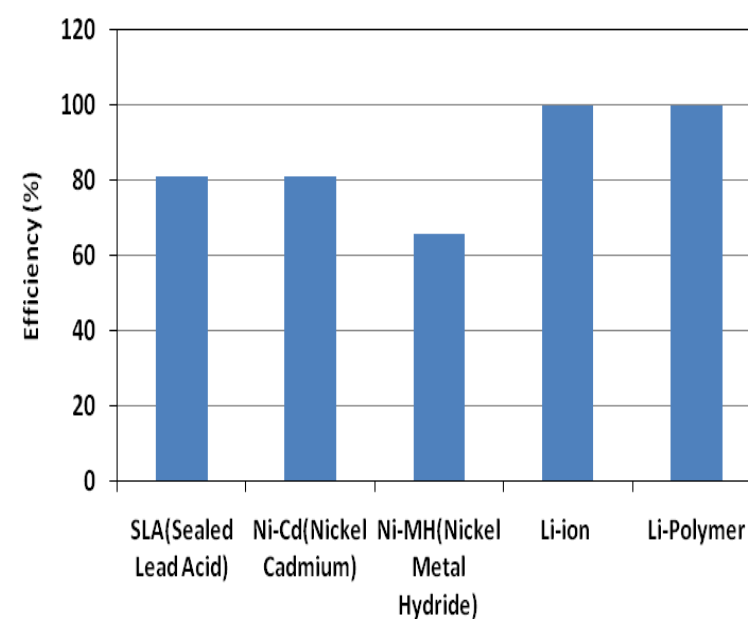

Figure. 2.Efficiency plot of batteries used in sensor nodes

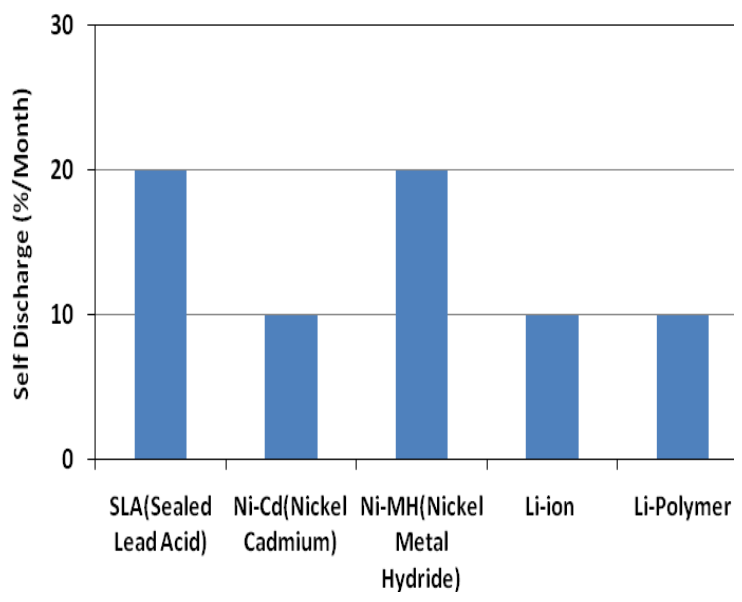

Figure. 3. Plot of self-discharge property of batteries

From Fig. 2 and Fig. 3 we observe that Li-ion and LiPolymer batteries have better efficiency and less selfdischarge properties, which make them suitable for sensor network application. This paper presents a review of currently available wireless sensor node structures and describes the energy efficient routing protocol schemes. It describes the hardware specifications of different wireless sensor node platforms and gives the possible energy 
harvesting methods to power the wireless sensor nodes. Energy harvesting may give a possible solution to the reduced lifetime problem of sensor nodes due to battery dependency. With evolving technology a number of solutions for wireless sensor nodes are available. Using these techniques differently capable sensor nodes that are suitable for different applications is possible. Sensor node topologies are very stringent and specific to the application. With improved technology wireless sensor networks have started to find a wide range of applications in daily lives. Their flexibility, self organization and fault tolerance capability makes them suitable for wide range of applications.

\section{REFERENCES}

[1] F. Akyildiz, W. Su, Y. Sankarasubramaniam, E. Cayirci, "Wireless sensor networks: a survey", Computer Networks, vol. 38, no. 4, pp. 393-422, 2002.

[2] Nikolaos A. Pantazis, Stefanos A. Nikolidakis and Dimitrios D. Vergados, "Energy-Efficient Routing Protocols in Wireless Sensor Networks: A Survey", IEEE COMMUNICATIONS SURVEYS \& TUTORIALS, VOL. 15, NO. 2, SECOND QUARTER 2013.

[3] Michael Healy, Thomas Newe and Elfed Lewis, "Wireless Sensor Node Hardware: A Review", IEEE conference publication, Digital object identifier10.1109/ICSENS.2008.4716517,Publication year 2008, Page(s):621-624.

[4] Atmel ATmega128, ATmega128L Datasheet, Rev. 2467X-AVR-06/11.

[5] Atmel AT91FR4081 Datasheet, Rev. 1386CATARM-02/02.

[6] Atmel ATmega163, ATmega163L Datasheet, Rev. 1142E-AVR-02/03.

[7] PIC18FXX2 Datasheet, 2006 Microchip Technology Inc.

[8] Atmel AT91FR4081 Datasheet, Rev. 1386CATARM-02/02.

[9] PIC18F6720 Datasheet, Microchip Technology Inc.

[10] PIC16F87XDatasheet, 2001 Microchip Technology Inc.

[11] MSP430F1611 Datasheet, Texas Instruments.

[12] Intel® PXA27x Processor Family Datasheet.

[13] Mai Ali, Lutfi Albasha, Nasser Qaddoumi Department of Electrical Engineering ,American University of Sharjah, Sharjah, United Arab Emirates, "RF Energy Harvesting for Autonomous Wireless Sensor Networks", Design and technology of integrated systems in nanoscale era(DTIS),2013 8th international conference, Digital object identifier 10.1109/DTIS.2013.6527782.

[14] Mile K. Stojčev1, Mirko R. Kosanović2, Ljubiša R. Golubović3, "Power Management and Energy Harvesting Techniques for Wireless Sensor Nodes", Telecommunication in modern satellite, Cable and broadcasting services,2009.TELSIKS'09 $9^{\text {th }}$ International conference: Digital object Identifier:
10.1109/TELSKS.2009.5339410, Publication year 2009,Page(s):65-72.

[15] www.memsindustrygroup.org/i4a/doclibrary/getfile.c fm?doc_id=481.

[16] Sravanthi Chalasani James M. Conrad, "A Survey of Energy Harvesting Sources for Embedded Systems", IEEE conference publication, Digital. object Identifier: 10.1109/SECON.2008.4494336, Publication year 2008, Page(s):442-447

[17] Sujesha Sudevalayam and Purushottam Kulkarni, "Energy Harvesting Sensor Nodes: Survey and Implications", IEEE COMMUNICATIONS SURVEYS \& TUTORIALS, VOL. 13, NO. 3, THIRD QUARTER 2011.

[18] Triet Le, Karti Mayaram, Fellow, IEEE, and Terri Fiez, Fellow, IEEE, "Efficient Far-Field Radio Frequency Energy Harvesting for Passively Powered Sensor Networks", IEEE JOURNAL OF SOLIDSTATE CIRCUITS, VOL. 43, NO. 5, MAY 2008.

[19] T. Sogorbl, J.V. Llario2, J. Pelegri3, R. Lajara, J. Alberola, "Studying the Feasibility of Energy Harvesting from Broadcast RF Station for WSN", I2MTC 2008 - IEEE International Instrumentation and Measurement Technology Conference Victoria, Vancouver Island, Canada, May 12-15, 2008

[20] Hubregt J. Visser, Senior Member IEEE, and Ruud J. M. Vullers, Senior Member IEEE, "RF Energy Harvesting and Transport for Wireless SensorNetwork Applications: Principles and Requirements", Proceedings of the IEEE, Volume: 101, Issue: 6, Digital object identifier:10.1109/JPROC.2013.2250891.

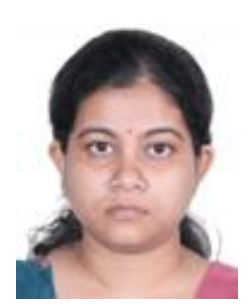

Sutapa Sarkar is pursuing her Master in Technology in Digital Electronics and Communication Engineering from M.V.J. College of Engineering, Bangalore, India. She completed Bachelor of Technology in Optics \& Opto-Electronics in 2006 from University of Calcutta, India. Before starting her post-graduation, she worked with HCL Technologies Ltd for three and half years in field of software testing in avionics domain (2007-2010). Her research interests cover wireless sensor networks, safe and secure communication, FPGA implementation. Email:sutapasarkar11@rediffmail.com.

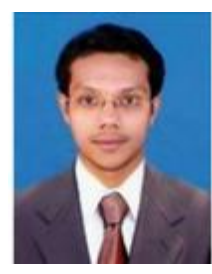

Hameem Shanavas .I is the Doctoral Research Scholar of Anna University, Coimbatore, India. $\mathrm{He}$ is currently working as Assistant Professor, Department of ECE, M.V.J. College of Engineering, Bangalore, India. $\mathrm{He}$ has completed his Bachelor Degree in Electronics and Communication (2006), Masters in VLSI Design (2008) and also he completed Masters in Business Administration (2009) He worked for various institutions 
in electronics and communication department round many states in India .He has more than 50 publication in his accpount. $\mathrm{He}$ is in editorial committee of many International Journals and reviewer for many Journals like IEEE Transactions, Science Direct etc. He is the member of Professional bodies like ISECE, IACSIT, IAEng, AASRC, IASIR, ISTE. His research areas are VLSI Physical Design and Testing, Low Power, DSP Implementations and CAD Algorithms. email: (hameemshan@gmail.com).

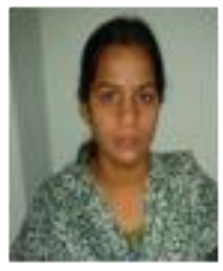

Bhavani. V working in MVJ College of Engineering as Assistant Professor.

How to cite this paper: Sutapa Sarkar, Hameem Shanavas .I, Bhavani V,"Energy Scavenging Technology and Components in WSN", IJCNIS, vol.6, no.3, pp.44-51, 2014. DOI: 10.5815/ijcnis.2014.03.06 